Gordana Globočki - Lakić

Branislav Sredanović

Davorin Kramar

Janez Kopač

DOI: $10.21278 /$ TOF.40204

ISSN 1333-1124

eISSN 1849-1391

\title{
MACHINABILITY OF C45E STEEL - APPLICATION OF MINIMUM QUANTITY LUBRICATION AND HIGH PRESSURE JET ASSISTED MACHINING TECHNIQUES
}

\begin{abstract}
Summary
In this paper, machinability of turned steel defined by monitoring of cutting forces, tool wear, surface quality and chip shape is presented. Experimental investigations were performed on untreated carbon steel C45E (hardness $45 \mathrm{HRc}$ ) and on surface induction hardened steel C45E (surface layer hardness $58 \mathrm{HRc}$ ). The analysis of machinability was performed under different cooling and lubrication conditions: conventional flooding, minimum quantity lubrication (MQL) and a hybrid machining method, i.e. high pressure jet assisted machining (HPJAM). The investigation was carried out for higher values of processing parameters. The results show the advantages of the advanced cooling and lubricating techniques, i.e. an increase in productivity and a reduction in production costs. The analysis of the results shows that the application of HPJAM gives superior machinability. Beside excellent chip breakability achieved in HPJAM, especially in hardened steel machining, significant improvement in tool life and reduction in cutting forces can be achieved.
\end{abstract}

Key words: $\quad$ HPJAM, MQL, modelling, machinability

\section{Introduction}

Machining processes should satisfy strict requirements in production: productivity, efficiency, surface quality, and additionally, reliability and sustainability. A new concept of machining technology, high efficiency machining (HEM), combines the advantages of high speed machining (HSM) in the finishing operation with improved material removal rates for the roughing operation $[1,2]$. In the modern production, there are tendencies to minimize or eliminate cooling lubricant, near-dry machining, introduce minimum quantity lubrication (MQL) and dry machining technologies or to utilize cryogenic or high pressure jet assisted machining (HPJAM) to meet the aforementioned requirements [3]. Studies have shown that the utilization of an accurate and reliable process monitoring system can increase the cutting speed by $10 \%$ to $50 \%$, reduce the machine downtime and predict the machine tool stopping, resulting in a total savings in the production of between $10 \%$ and $40 \%[3,4]$. Progress is not possible without the knowledge about the machinability of materials and expert systems used in the selection of suitable machining parameters based on the machinability analysis [5]. 
The basic functions of cooling-lubrication fluid (CLF) are friction reduction, tool life extension, reduced heat generation and improvement of chip evacuation $[6,7]$. The effect of cooling and lubricating depends on fluid flow parameters, fluid characteristics and delivery technique. The greatest progress in the development of high productive machining processes has been achieved in the development of special CLF delivery techniques, such as MQL and a hybrid machining process HPJAM. Maruda et al. analyzed the influence of MQL system parameters on cutting parameters [8]. The influence of droplet velocity at the MQL nozzle outlet on the active medium atomization angle and the number of droplets supplied to the cutting zone were also studied by Maruda et al. [9]. Experimental and numerical simulations of liquid film formation in MQL for different rotating velocities of a milling tool, based on the Reynolds-Average Navier-Stokes formulation and the multiphase Lagrangian model was performed by Duchosal et al. [10]. Nadolny et al. described a new system for centrifugal supply of oil mist in the internal cylindrical grinding process. The formation mechanism and distribution characteristics of suspended micro-particles in the MQL grinding have been recently investigated by Jia et al. [12]. The concept of HPJAM is to inject a high pressure jet of CLF in the cutting zone. HPJAM has been established as a method for achieving a substantial increase in the removal rate and productivity in machining [13]. The advantage of this method is reduction in cutting temperature and tool wear and improvement of chip breakability and evacuation especially in hard-to-machine materials [14, 15].

The problem with machinability estimation is that some material may have good machinability. Machinability estimation must be based on the consideration of many criteria simultaneously, e.g. Boulger et al. [16] proposed that the machinability is expressed by the economy of the process with the use of a special machinability test. Lee and Shaffer [17] suggested that machinability can be defined by the thermodynamic number. Enache et al. [18] developed a global model of machinability which contains more criteria. Rao and Gandhi [19] used the principles of the matrix and graph theory for defining the absolute material machinability, named "matrix model". In this paper, a vector based method of the machinability definition is used. The vector based method, which consists of several machinability criteria, is described in [20]. Beside the vector method, in this paper, machinability is also defined by the index method introduced by Theile et al. [21] based on energy and economic aspects and the aspect of machining quality.

The analysis of the machining energy balance, effect of chip formation, tool life and quality of machined surface was included in order to analyse the machinability when applying different CFL delivery techniques: flooding, MQL and HPJAM. The studies that are presented in this paper are related to the analysis of the advanced CLF delivery techniques usage, with the aim of defining the directions for increasing productivity and efficiency of the machining process. Studies presented in this paper focused on effects of different CLF delivery techniques in the field of higher cutting speeds and feeds which contributed to the expansion of the region of operability and higher productivity and as such better machinability.

\section{Experimental procedure}

Experimental investigation and machinability evaluation under different cutting conditions and different cooling-lubrication techniques in turning, namely conventional flooding, MQL and HPJAM, were carried out. The experimental investigation was performed on a conventional lathe. In the flooding operation, CLF was delivered at the top of the machining zone, from a distance of approximately $150 \mathrm{~mm}$ at $61 / \mathrm{min}$. CLF was directed to the non-machined workpiece surface and the rake surface of the cutting tool insert. In the MQL technique, CLF was delivered using a special device which utilizes compressed air to 
form oil mist in the mixing chamber. In the machining operation, due to the effect of the spray, the tool was enveloped in a thin layer of emulsion. Pressure was set at $0.3 \mathrm{MPa}$ and the flow rate at $0.0005 \mathrm{l} / \mathrm{min}$. In the MQL technique, the spray nozzle was installed at a distance of $30 \mathrm{~mm}$, perpendicular to the cutting edge, with an angle of $30^{\circ}$ with respect to the rake face of tool. In HPJAM, the jet was directed toward the cutting edge at a low angle directly between the rake face and the chip. For this application, a conventional universal lathe was fitted with a high pressure plunger pump with a flow rate capacity of $10 \mathrm{l} / \mathrm{min}$ and pressure of $150 \mathrm{MPa}$. A standard sapphire nozzle commonly used in water jet cutting applications was installed at a distance of $30 \mathrm{~mm}$ from the tool cutting edge in order to assure its use in the jet core zone and avoid variations in the jet diameter and radial distribution of the pressure. The jet was directed toward the cutting edge at a low angle of $5^{\circ}$ with respect to the tool rake face.

Workpiece materials used in the experimental investigation were construction steels used for highly loaded parts in mechanical engineering, namely, untreated carbon steel C45E with a hardness of $45 \mathrm{HRc}$ and surface induction hardened steel C45E with a surface layer hardness of $58 \mathrm{HRc}$. All experiments were carried out using a CLF with 3\% emulsion of vegetable oil.

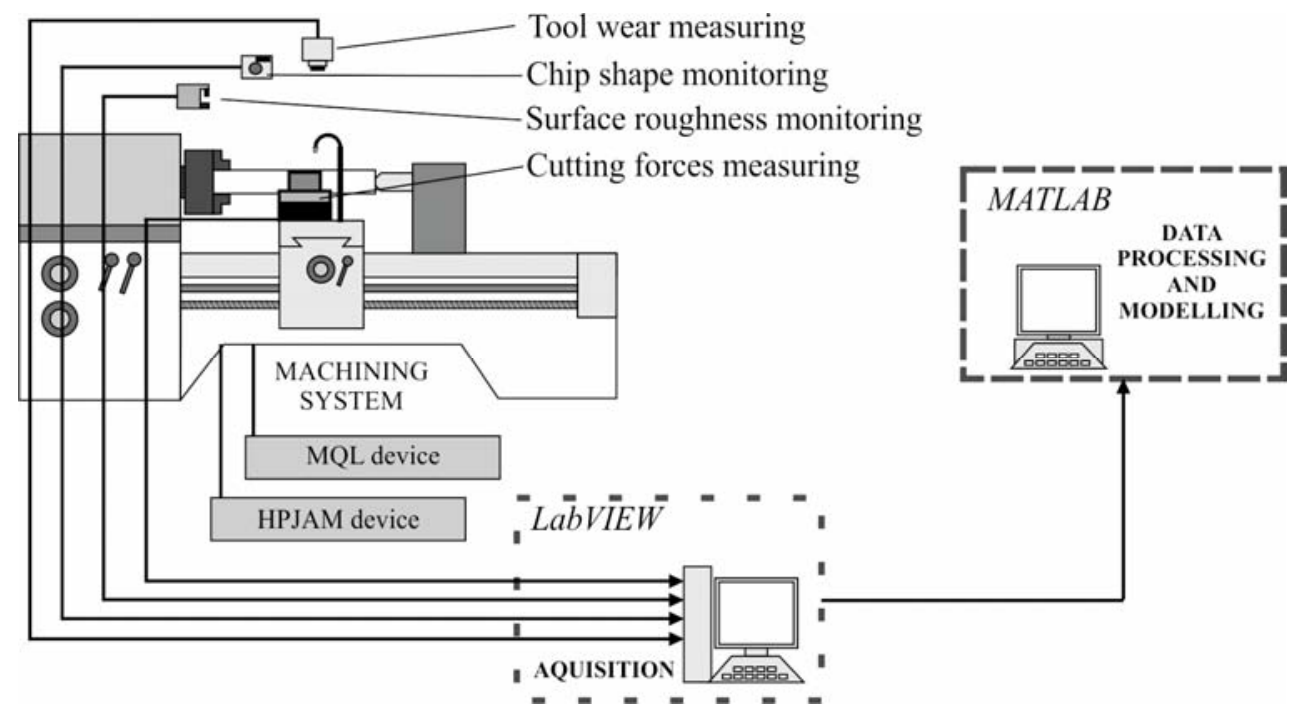

Fig. 1 Data flow in measuring and monitoring

The following process output parameters were monitored in the experiments: cutting forces $\left(F_{c}, F_{f}\right.$, and $\left.F_{p}\right)$, flank tool wear $(V B)$, arithmetic average roughness height $(R a)$ and maximum height of roughness $\left(R_{y}\right)$. At the same time the chips were collected and the chip shape was analysed (Fig. 1). Kistler dynamometer was used to measure cutting force components in the turning operation. For the processing of the measured signals the LabVIEW software was used. Data processing was performed with the MATLAB software package. Monitoring and measurement of tool wear was performed by using a tool microscope TM Mitutoyo 510, equipped with a high-resolution camera. Surface roughness was measured by using a mobile measuring device Mitutoyo SURFTEST SJ-301.

\section{Results and discussion}

The index method was used to define the material machinability applying three aspects: the energy aspect, i.e. the cutting forces, the economic aspect, i.e. wear of the cutting tool and the quality aspect, i.e. surfaces roughness. Machinability was also evaluated by applying the vector model of universal machinability [20]. Both machinability evaluation methods are compared and discussed at the end of this chapter. 


\subsection{Analysis of the results on untreated carbon steel C45E}

In the turning operation of the untreated C45E carbon steel having hardness of $45 \mathrm{HRc}$, a carbide cutting tool SNMG 120408 NMX was used. A tool holder PSDN 2525 M12 with an inclination angle of $45^{\circ}$ was utilized. Cutting parameters were set so as the highest productivity would be achieved in the turning operation, with the values as follows: cutting depths $a_{p}[\mathrm{~mm}]: 1.5,2.0$ and 2.5 ; feed $f[\mathrm{~mm} / \mathrm{rev}]: 0.224,0.280,0.355$ and 0.400 ; and cutting speed $v_{c}[\mathrm{~m} / \mathrm{min}]: 210,310$ and 400 . In the operation of the HPJAM sapphire nozzle of 0.4 $\mathrm{mm}$ in diameter the pressure of $50 \mathrm{MPa}$ and the flow of $21 /$ min were used.

Table 1 Cutting force regression models for different CLF delivery techniques (C45E - $45 \mathrm{HRc)}$

\begin{tabular}{|l|c|c|c|c|c|}
\hline $\begin{array}{l}\text { Material: C45E } \\
\text { Tool: Carbid SNMG 1204 08 NXM }\end{array}$ & $\begin{array}{c}\text { Colleration } \\
\text { coefficient }\end{array}$ & $\begin{array}{c}\text { Relative } \\
\text { error }(\%)\end{array}$ & $\begin{array}{c}\text { Flood } \\
k_{i}\end{array}$ & $\begin{array}{c}\text { MQL } \\
k_{i}\end{array}$ & $\begin{array}{c}\text { HPJAM } \\
k_{i}\end{array}$ \\
\hline$F_{c}=2485 \cdot a^{0.878} \cdot f^{0.844} \cdot v^{-0.047} \cdot k_{1}$ & 0.99 & 1.9 & 1 & 1 & 1 \\
\hline$F_{f}=1154 \cdot a^{0.838} \cdot f^{0.391} \cdot v^{-0.157} \cdot k_{2}$ & 0.93 & 3.9 & 0.99 & 0.96 & 1.02 \\
\hline$F_{p}=822 \cdot a^{0.589} \cdot f^{0.644} \cdot v^{-0.052} \cdot k_{3}$ & 0.93 & 3.7 & 0.98 & 0.93 & 0.95 \\
\hline
\end{tabular}

Cutting force modelling was performed using the regression analysis. Table 1 shows the developed regression equations. The impact of the CLF technique is given by the coefficients $k_{i}$. The regression models have an error of less than $4 \%$. It can be concluded from the results of the experimental studies shown in Fig. 2 that the application of HPJAM significantly reduces the value of feed and passive cutting force. The cutting force values decreased by $7 \%$ when HPJAM was used in comparison with the conventional flood technique.

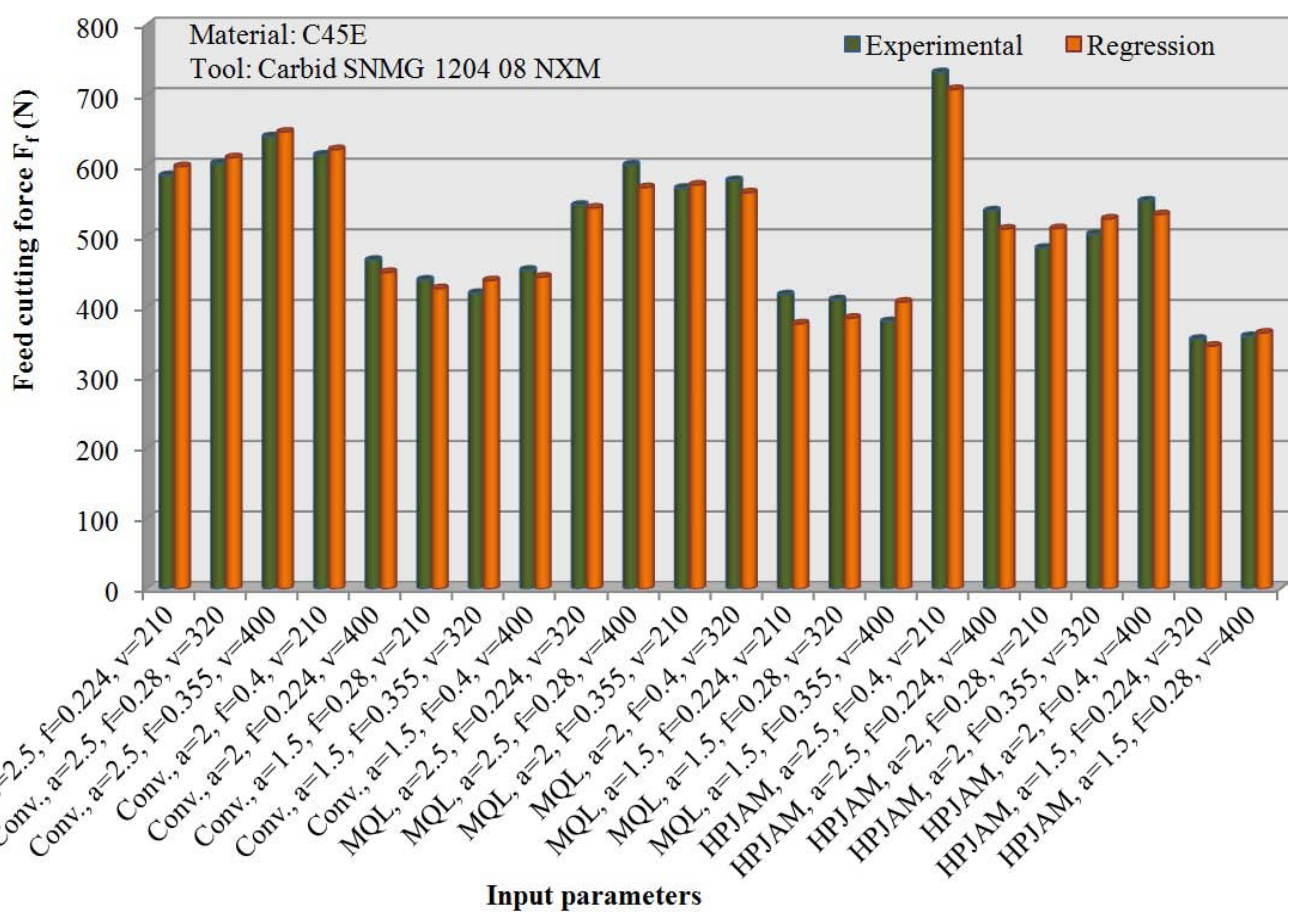

Fig. 2 Comparison of feed cutting forces in different models for C45E turned steel (45 HRc)

One of the main indirect indicators of the machining process condition is the chip shape. In this paper, the standard classification and acceptable estimation of the chip shape was used. The results of the experimental investigation with conventional flooding are presented in Fig. 3. When the MQL technique was used, chips were dark, which indicates that in the cutting area a larger amount of heat was generated and dissipated through the chips. It can be concluded that MQL provides good lubrication conditions, but low cooling effects of the 
Machinability of C45E Steel - Application of Minimum Quantity Lubrication and High Pressure Jet Assisted Machining Technique
G. Globočki-Lakić, B. Sredanović, D. Kramar, J. Kopač

cutting zone. Based on the chip shape, it can be concluded that the use of MQL provides favourable shapes of the chip under all analysed machining conditions (Fig. 4). By applying HPJAM favourable chip shapes were achieved in all combinations of cutting regimes. The chips were bright, which indicates better heat conduction (Fig. 5).

\begin{tabular}{|c|c|c|c|}
\hline Time T [min] & Flank face & Rake face & Chip shape \\
\hline 0.93 & 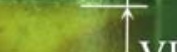 & & \\
\hline 7.23 & & & \\
\hline
\end{tabular}

Fig. 3 Tool wear and chip shape in conventional cooling in turning of C45E (45 HRc)

\begin{tabular}{|c|c|c|c|}
\hline Time $\mathrm{T}$ [min] & Flank face & Rake face & Chip shape \\
\hline 1.10 & VB & & \\
\hline 9.65 & & & \\
\hline
\end{tabular}

Fig. 4 Tool wear and chip shape in MQL in turning of C45E (45 HRc)

\begin{tabular}{|c|c|c|c|}
\hline Time $\mathrm{T}$ [min] & Flank face & Rake face & Chip shape \\
\hline \multicolumn{4}{|l|}{1.90} \\
\hline 8.52 & & & \\
\hline & & & \\
\hline
\end{tabular}

Fig. 5 Tool wear and chip shape in HPJAM in turning of C45E (45 HRc)

In comparison with other CLF delivery a technique HPJAM also provides a stable tool wear process and is therefore acceptable in highly productive automatic machining processes. Tool wear in HPJAM is uniform and less notch wear is recognized compared to other two CLF delivery techniques (Figs. 3-5). Even more benefits can be achieved by applying HPJAM when tool life is considered (Fig. 6). Tool wear criterion $V B=0.3 \mathrm{~mm}$ was used in the analysis. When HPJAM was applied, tool life was almost three times longer compared to MQL and almost four times longer than in the case of conventional flooding.

A comparison between the surface roughness parameters of different CLF delivery techniques is shown in Fig. 7. There is not much difference perceived between MQL and 
HPJAM, while slightly lower roughness was achieved with conventional flooding. The maximum surface roughnesses $R_{y}$ was modelled using the regression analysis for each CLF delivery technique depending on the machining time (Table 2), where $f$ is the feed rate and $r$ is the tool nose radius.

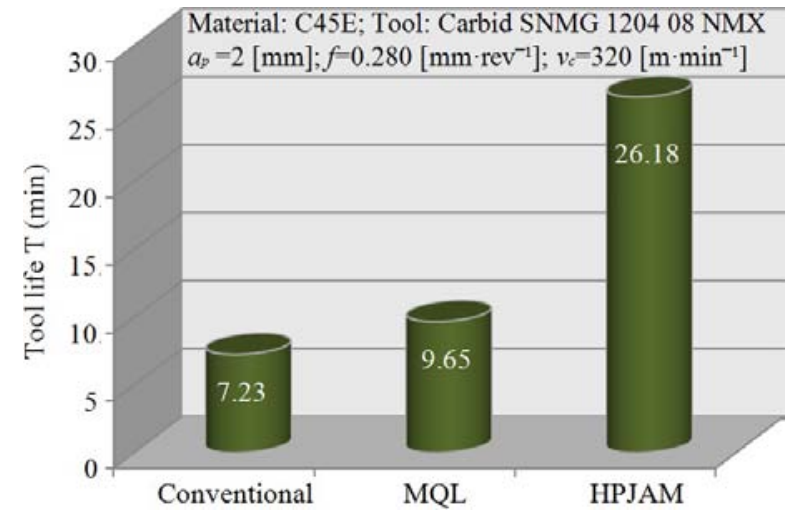

Fig. 6 Tool life for different CLF techniques

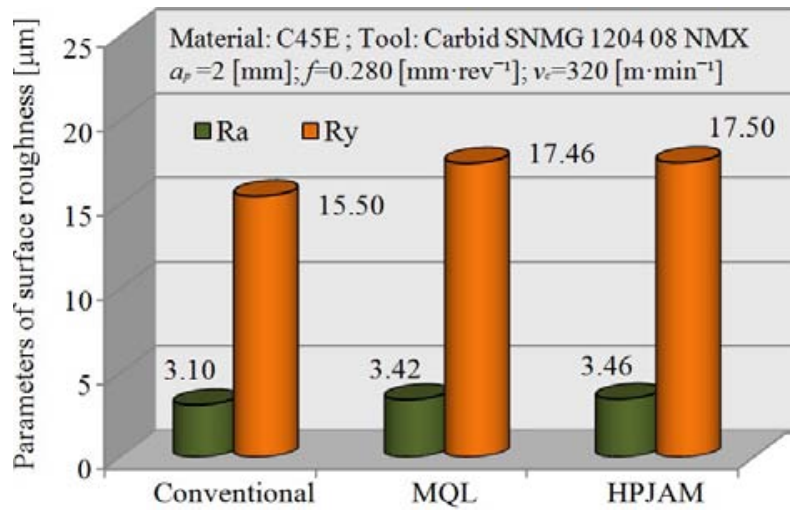

Fig. 7 Surface roughness in turning of C45E steel

Table 2 Regression models of surface roughness with respect to tool wear (C45E - $45 \mathrm{HRc})$

\begin{tabular}{|l|l|}
\hline \multicolumn{2}{|l|}{ Material: C45E; $a_{p}=2.0 \mathrm{~mm} ; v_{c}=320 \mathrm{~m} / \mathrm{min} ;$ Tool: Carbide SNMG $120408 \mathrm{NXM}$} \\
\hline Conv. & $R_{y}=0.635 \cdot T+\left(f^{2} \cdot 10^{3} /(8 \cdot r)\right)$ \\
\hline MQL & $R_{y}=0.676 \cdot T+\left(f^{2} \cdot 10^{3} /(8 \cdot r)\right)$ \\
\hline HPJAM & $R_{y}=0.334 \cdot T+\left(f^{2} \cdot 10^{3} /(8 \cdot r)\right)$ \\
\hline
\end{tabular}

The regions of operability of all three cooling lubrication techniques and different depths of the cut are shown in Fig. 8. They are based on the assessed chip suitability. From the analysis of the technological areas, it can be concluded that the HPJAM technique can be more widely used in steel turning. The HPJAM technique offers preferred chip shapes for all combinations of cutting parameters. In this case, the chips were bright, which indicates that with the application of CLF the generated heat was removed from the cutting zone.

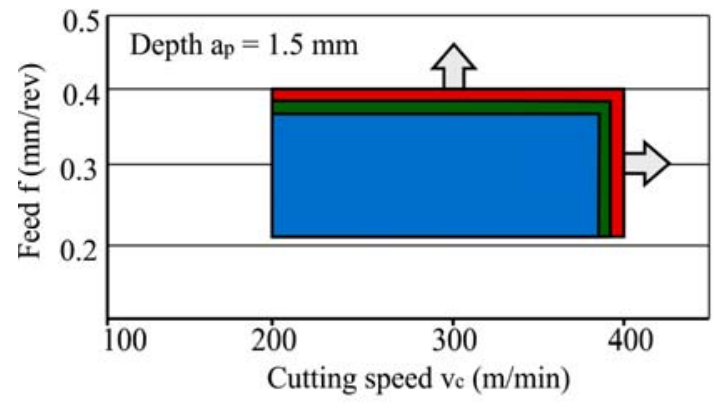

Conventional

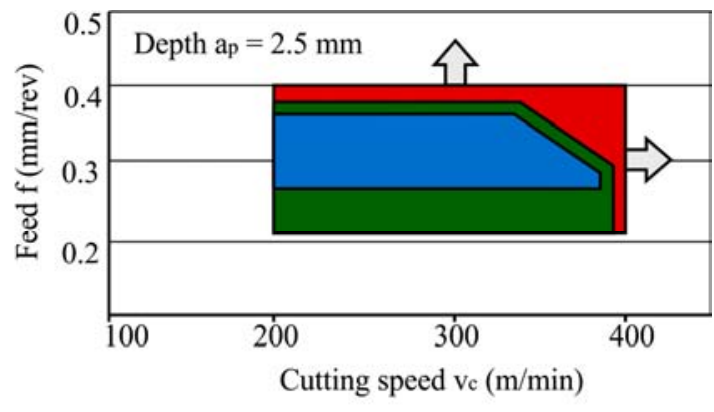

MQL
HPJAM

Fig. 8 Expansion of region of operability in the case of MQL and HPJAM technique (C45E - 45 HRc)

\subsection{Analysis of results on surface hardened carbon steel C45E}

In the turning operation of the surface induction hardened steel $\mathrm{C} 45 \mathrm{E}$ having a surface layer hardness of $58 \mathrm{HRc}, \mathrm{Al}_{2} \mathrm{O}_{3}$ coated carbide cutting tools SNMA $120408 \mathrm{KR} 432$ were used. The cutting inserts had no chip breaking geometry on the rake face. For the analysis of the jet pressure influence on the cutting process, different CLF pressures were applied, while the cutting speed, $v_{c}=98.5 \mathrm{~mm} / \mathrm{min}$, feed rate, $f=0.25 \mathrm{~mm} / \mathrm{rev}$ and depth of cut, $a_{p}=2 \mathrm{~mm}$, were kept constant. At the pressures of $10 \mathrm{MPa}$ and $30 \mathrm{MPa}$, a relatively good breakability of chips was observed. In Fig. 9, the influence of the CLF pressure on the cutting forces is 
Machinability of C45E Steel - Application of Minimum Quantity Lubrication and High Pressure Jet Assisted Machining Technique
G. Globočki-Lakić, B. Sredanović, D. Kramar, J. Kopač

shown. There was no decrease in the main cutting force when HPJAM was applied. However, the feed and the radial force decreased as soon as pressurized CLF was used (approx. by 10\% in both cases) compared to conventional flooding, but there was no significant trend in the force decrease with the increase in pressure.

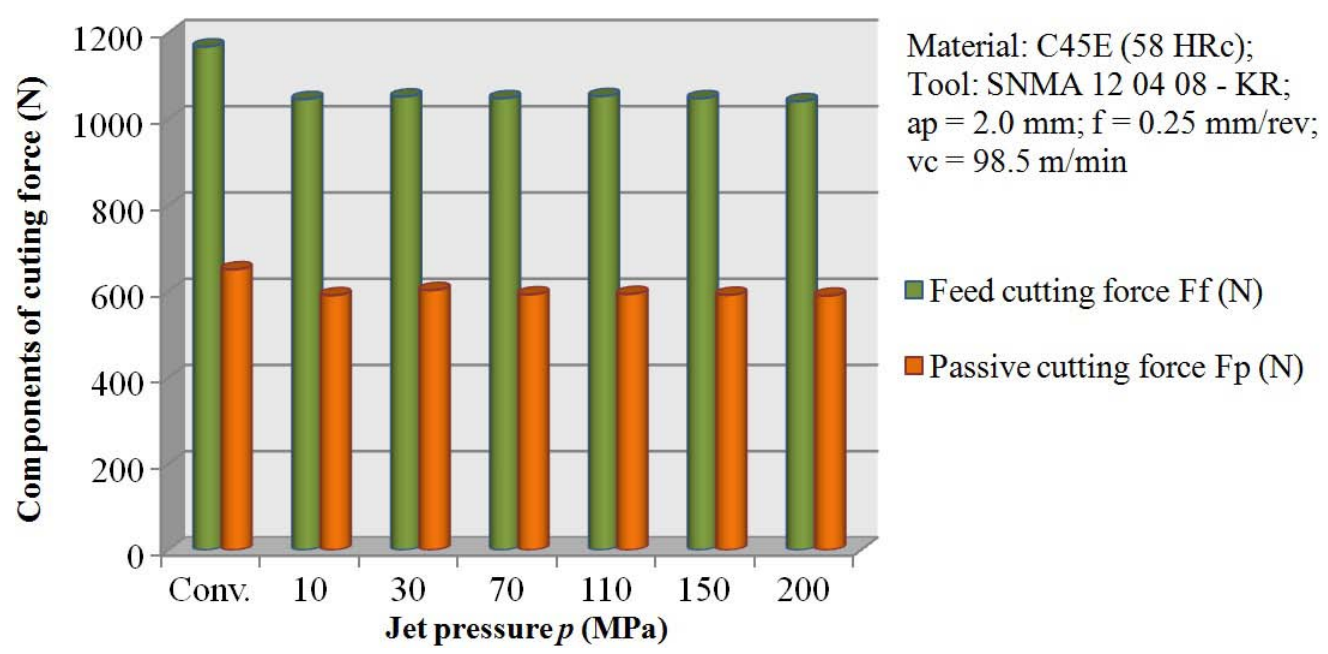

Fig. 9 Feed and penetration component of cutting force in HPJAM of C45E (58 HRc)

Figs. 10 and 11 show comparisons between tool wear and chip formation in conventional flooding and HPJAM. The distribution of wear along the flank face is uniform in both cases. We can observe some notching on the right-hand side probably due to friction and sharp edges of the chips at the depth of the cut line. The main advantage reported in every case of HPJAM is excellent chip breakability. We have noticed that from the pressure of 110 $\mathrm{MPa}$ the size of the chips is similar and that an increase in pressure gives no further improvements.

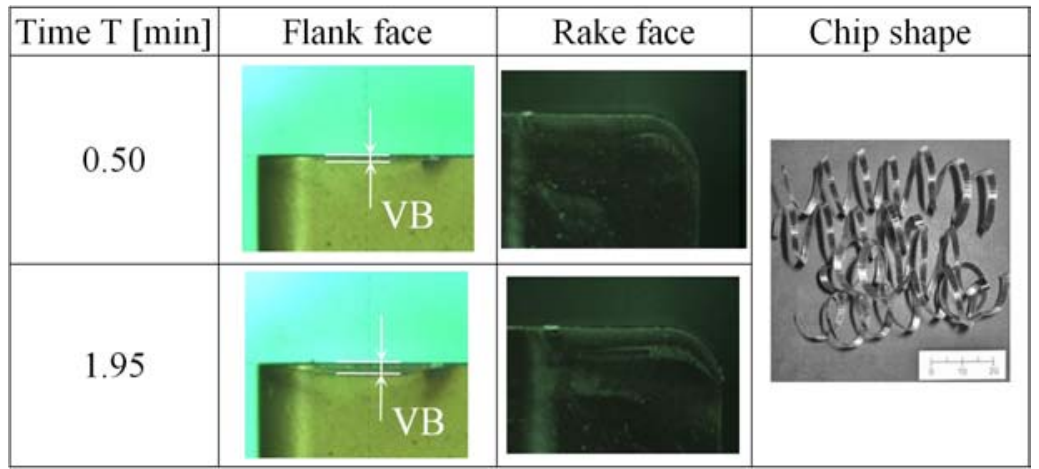

Fig. 10 Tool wear and chip shape in conventional cooling in turning of C45E (58 HRc)

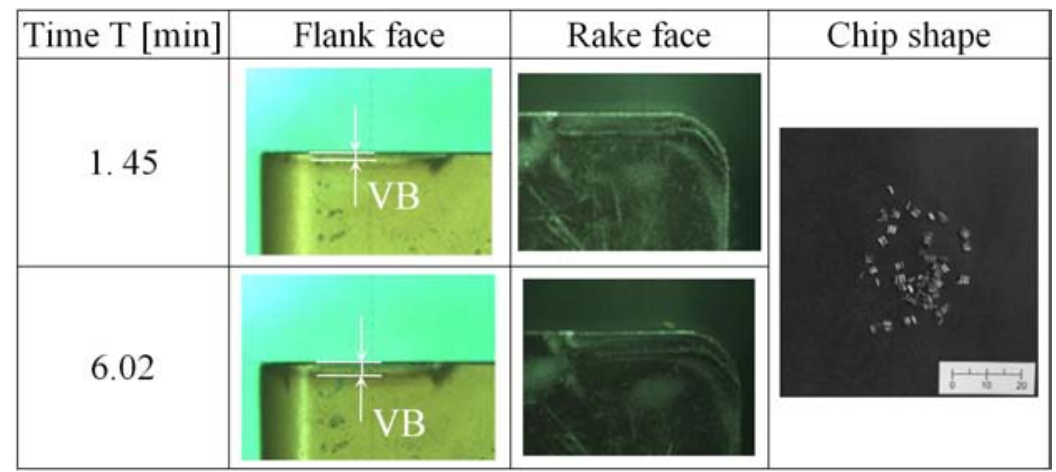

Fig. 11 Tool wear and chip shape in HPJAM of C45E (58 HRc) 
Fig. 12 shows a comparison of the tool flank face wear under both conventional and HPJAM conditions. For the selected criteria $\mathrm{VB}=0.1 \mathrm{~mm}$, the tool life in the case of HPJAM was about $10 \mathrm{~min}$, which is approximately five times longer than in the case of conventional cooling. It should be pointed out that the consumption of coolant in the case of HPC is more than four times lower than in the case of conventional cooling.

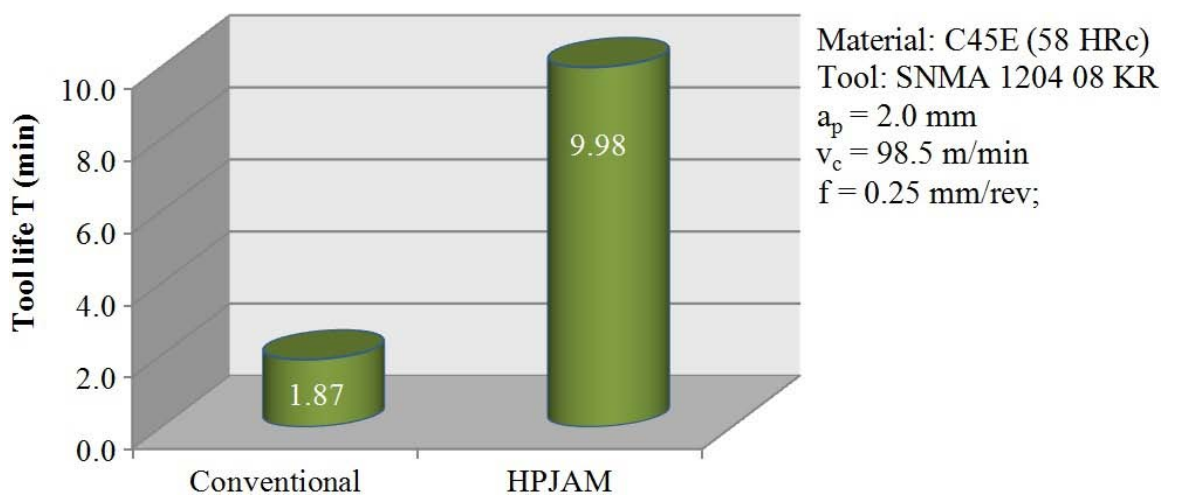

Fig. 12 Comparison of tool wear in turning of C45E (58 HRc) using both cooling techniques

Only slight improvement in surface roughness was achieved by the application of HPJAM compared to conventional flooding (see Fig. 13). Since the application was in the semi-finishing and roughing operations the effect is not so important.

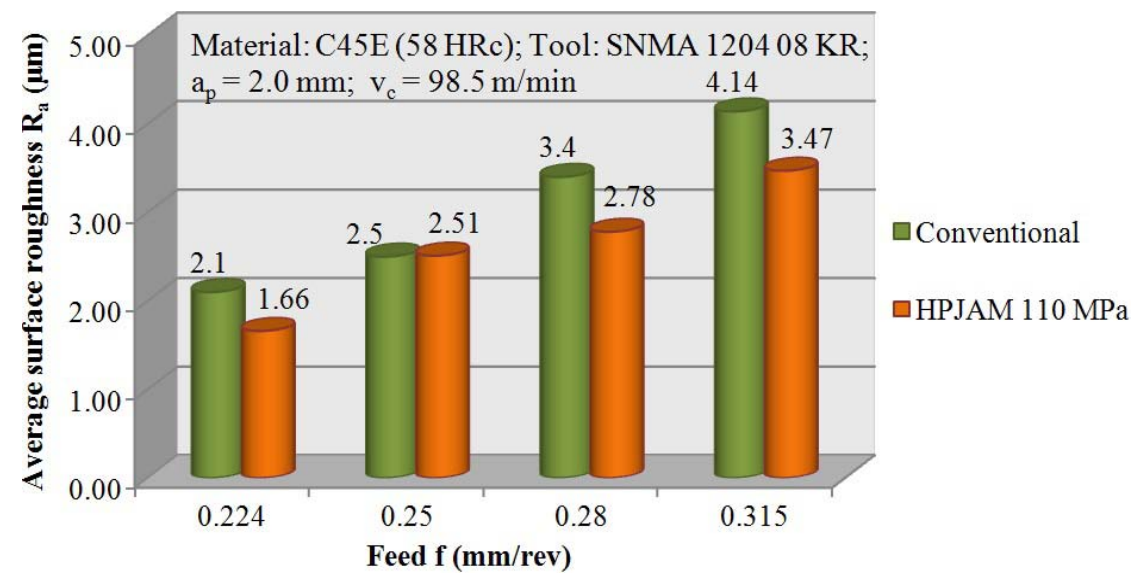

Fig. 13 Surface roughness Ra in turning of C45E (58 HRc) using different CLF delivery techniques

The machining capabilities of conventional flooding and the HPJAM method were compared with respect to chip breakability, tool wear, tool life and cutting forces. Both cooling and lubrication conditions are characterized by process regions of operability of the employed tool-material pair [22]. Under both cooling and lubrication conditions, the methodology has been applied by observing the specific cutting force, roughness of the machined surface, shape of the chips and vibrations of the system.

The two resulting working areas are presented in Fig. 14. The major concluding remark regarding the advantages of HPJAM over conventional flooding in the hard turning operation of steel with coated carbide tools is that the region of operability for a given tool-material pair is extended. An approximately $45 \%$ increase in the maximum achievable cutting speed and a $25 \%$ increase in the maximum achievable feed rate were proven. 
Machinability of C45E Steel - Application of Minimum Quantity Lubrication and High Pressure Jet Assisted Machining Technique
G. Globočki-Lakić, B. Sredanović, D. Kramar, J. Kopač

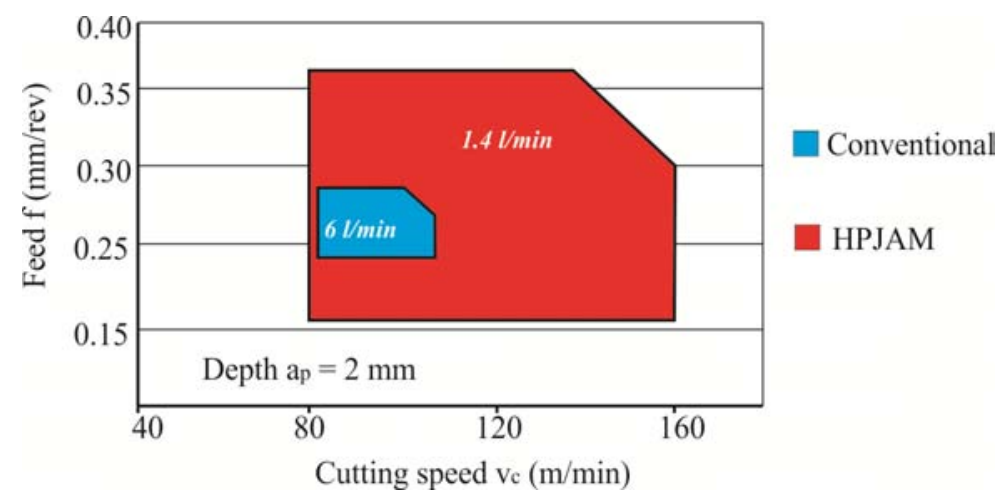

Fig. 14 Expansion of region of operability in the case of HPJAM technique for C45E (58 HRc)

\subsection{Machinability evaluation}

First, machinability was defined by the index method based on the economic and energy aspects and the aspect of quality of machining. The results are presented in Figs. 15 and 16. Based on the index machinability method it can be concluded that HPJAM gives the best machinability of untreated and hardened C45E steel regarding tool life and forces (energy and economic aspect), while best roughness (quality aspect) is achieved by conventional flooding. As shown in the previous chapter the main benefit of HPJAM compared to other coolinglubrication techniques is tool life prolongation. The machinability index in terms of tool wear for HPJAM in the case of untreated steel C45E is 3.4 times higher and in the case of hardened steel even 5.4 times higher compared to other CLF delivery techniques.

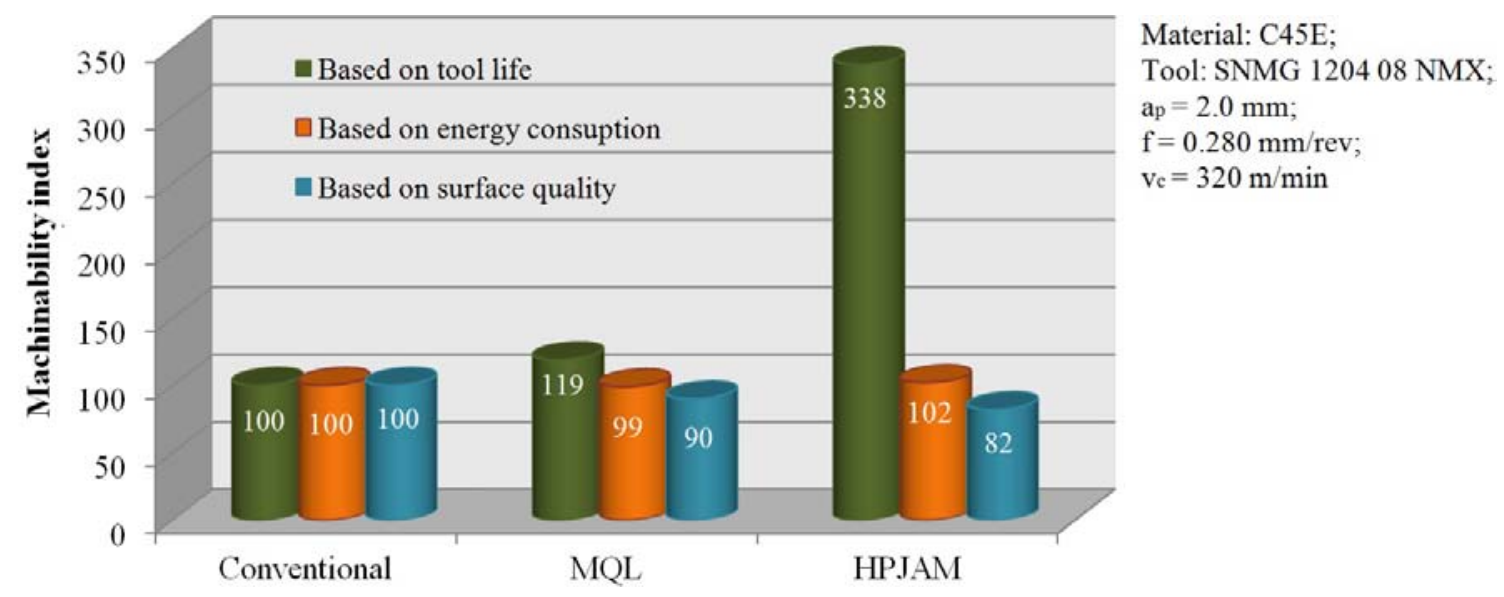

Fig. 15 Indexes of machinability of untreated steel C45E (45 HRc)

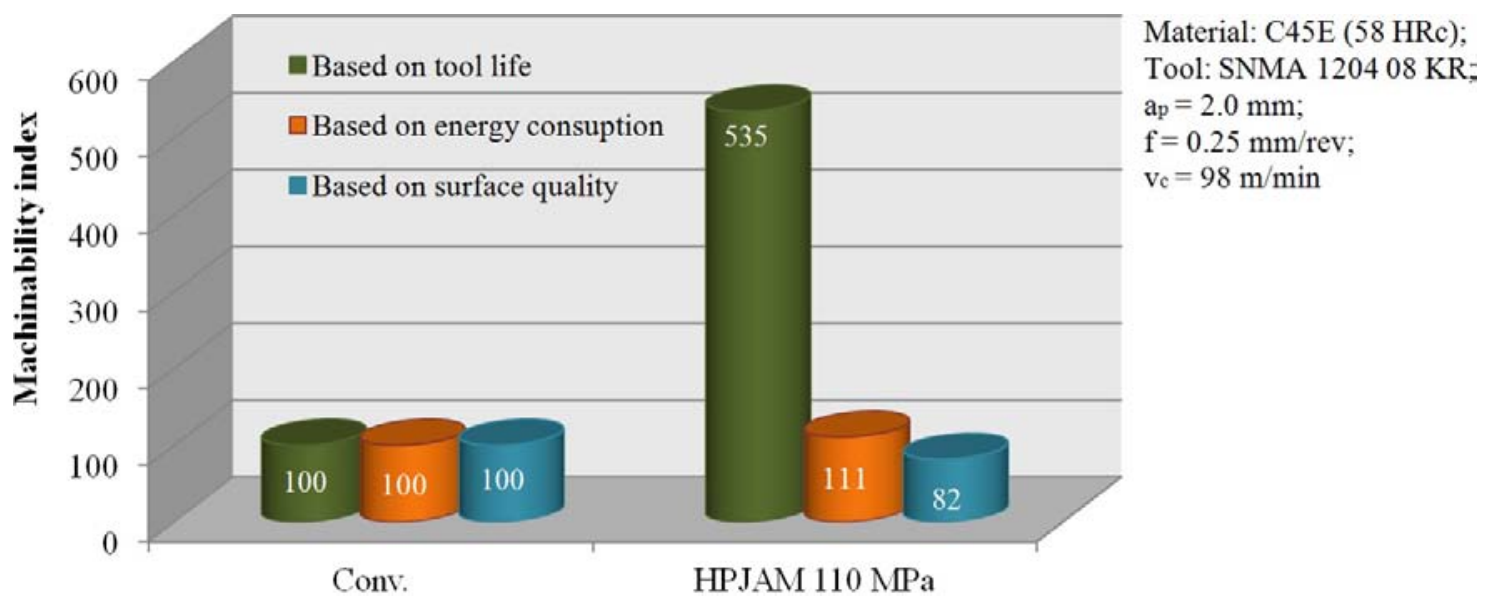

Fig. 16 Indexes of machinability of hardened steel C45E (58 HRc) 
Since the index method defines the machinability of materials only from one aspect, in this paper, the vector method as „universal machinability” was applied. The vector model considers several output process parameters simultaneously, such as cutting force, tool wear and surface roughness. Fig. 17 shows the results of the machinability evaluation of different cooling-lubrication conditions and both steel types using the vector model.

Fig. 17 shows that HPJAM of untreated C45E (45 HRc) at $f=0.28 \mathrm{~mm} / \mathrm{rev}$ and $v_{c}=320 \mathrm{~m} / \mathrm{min}$ gives the best "universal machinability" when the aspects of tool wear, cutting forces and surface quality are considered. Compared to conventional flooding and the MQL technique, when HPJAM is applied more than 2 times higher machinability is achieved. In the case of hard turning of C45E ( $58 \mathrm{HRc})$ the machinability defined by the vector model is almost 2.5 times higher when HPJAM is used compared to conventional flooding. This is particularly important because the application of the HP technology in hard turning of steel with coated carbide tools gives excellent "universal machinability" for all three aspects simultaneously. It can be concluded that in hard turning carbide tools can replace expensive CBN tools when HPJAM is applied.

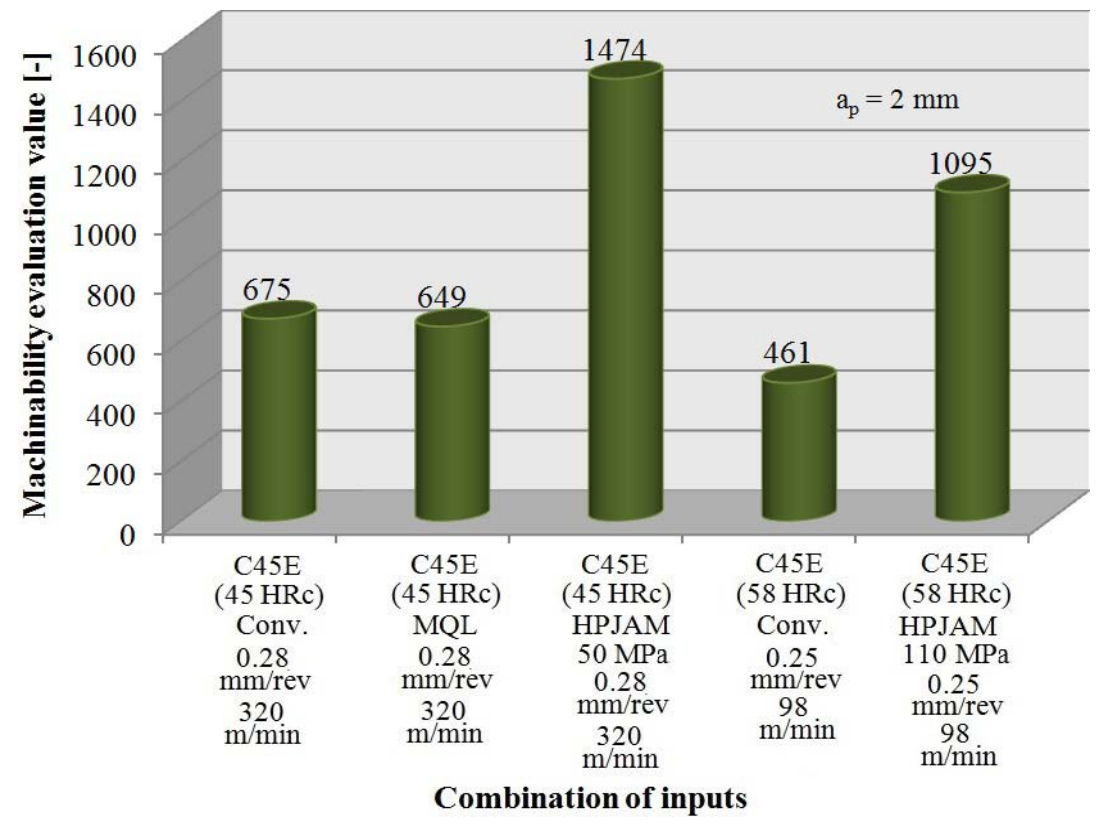

Fig. 17 Machinability values evaluated using vector model for different material types and CLF delivery technique criteria

Fig. 18 shows the estimation of machinability performed by using indirect cutting process parameters, such as chip shape, material removal rate etc. In these analyses, the best machinability of hardened steel was also achieved by the application of HPJAM. It should be noted that in comparison with conventional flooding the application of the HPJAM method extends the area of operability, significantly improves chip breaking, reduces the build-up edge (BUE) at lower speeds and the cutting fluid consumption few times. This is also important in terms of reduction of costs of machining and ecology. 
Machinability of C45E Steel - Application of Minimum Quantity Lubrication and High Pressure Jet Assisted Machining Technique
G. Globočki-Lakić, B. Sredanović, D. Kramar, J. Kopač

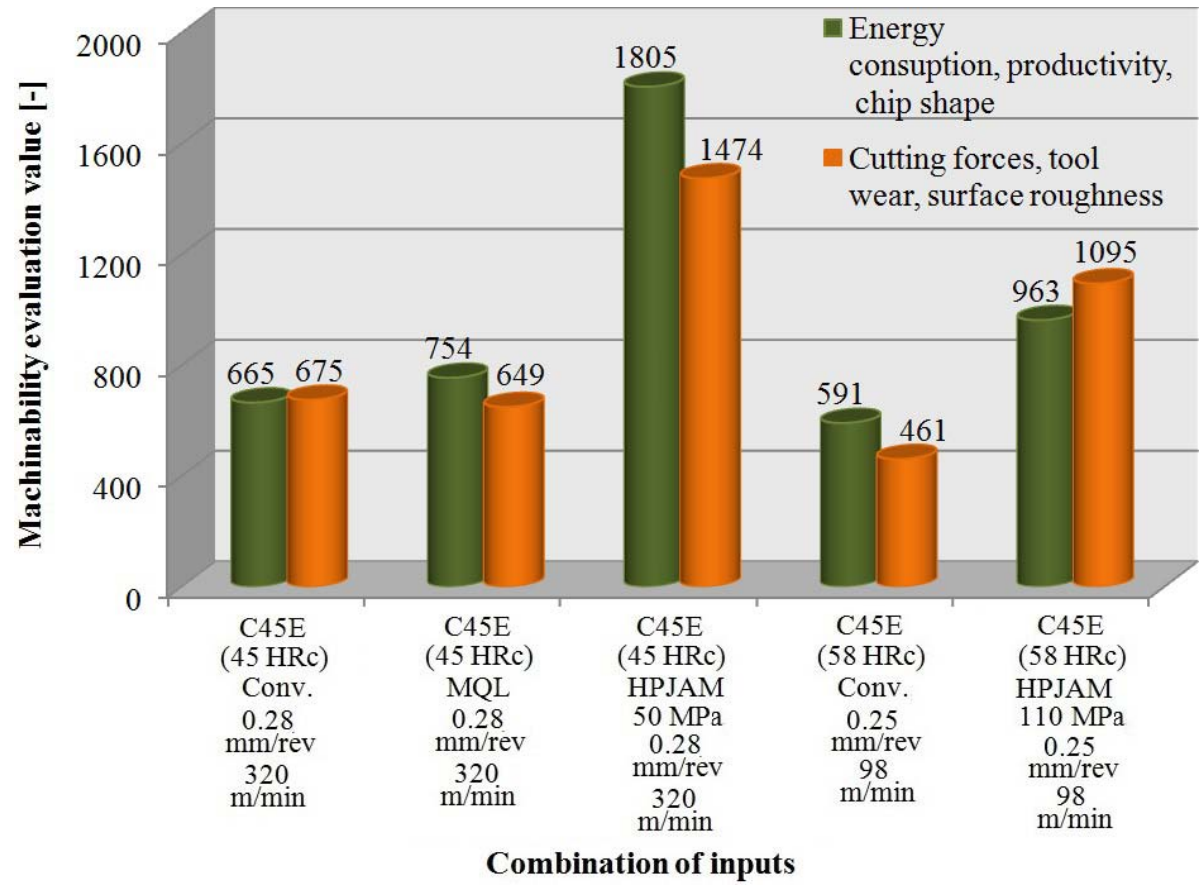

Fig. 18 Machinability evaluation values of C45E with respect to different criteria and dosing techniques

Results of the machinability evaluation by using the vector model show a very high correlation with other machinability models, such as the „global model" and the "matrix model", described in the introduction to this paper (see Fig. 19). In all cases, regardless of the material type, HPJAM gives superior machinability compared to other two CLF delivery techniques.

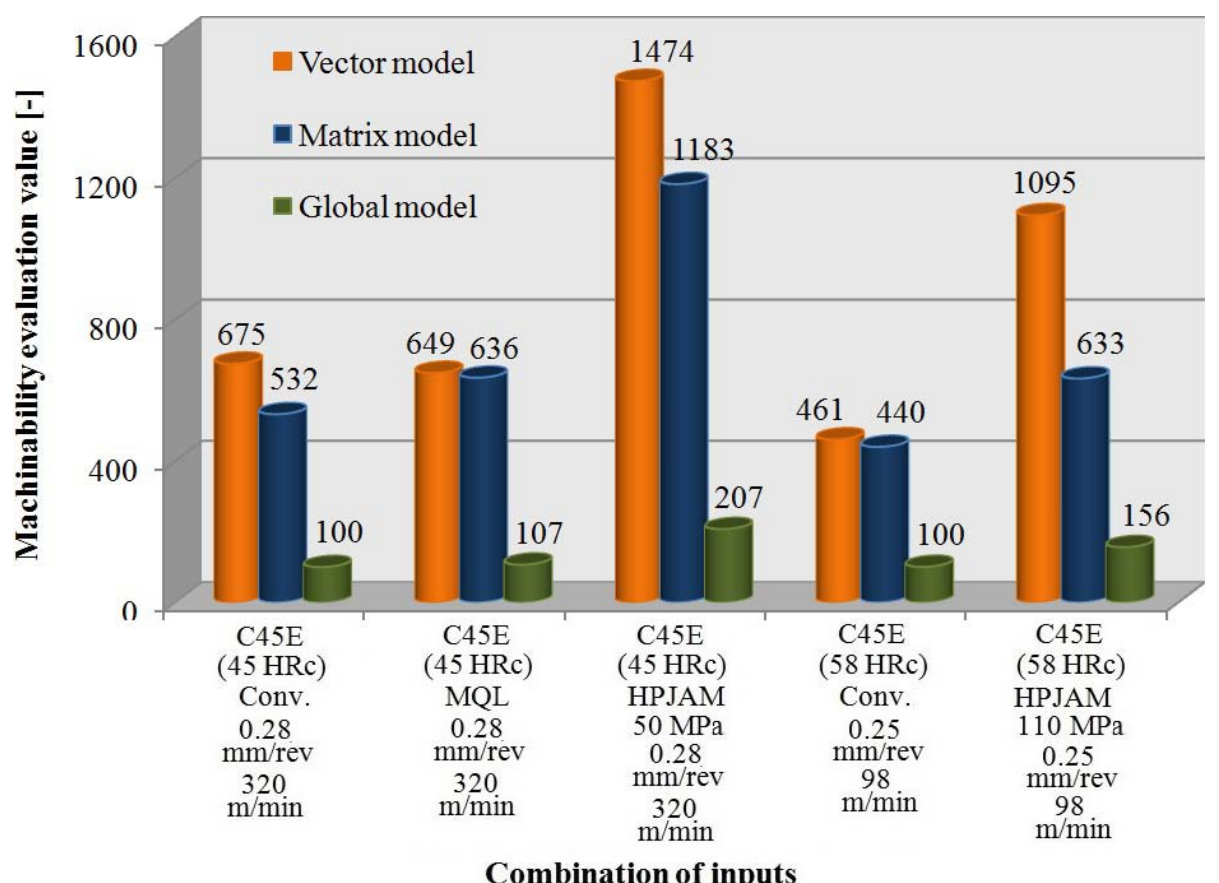

Fig. 19 Machinability evaluation of C45E with different hardness values (45 HRc and $58 \mathrm{HRc}$ ) by means of different models 


\section{Conclusion}

The aim of this study was to point out the importance of machining process modelling and material machinability evaluation; the importance and extensive use of modern CLF dosing techniques, especially the MQL and the HPJAM technique in the machining of different materials; and the importance and applicability of the new vector model for defining "universal" machinability, which is based on the simultaneous consideration of several criteria. Since machinability of materials is a very important technological category, this paper analyses the influence of different CLF dosing techniques on machinability of different materials. Cutting forces, intensity of flank tool wear and parameters of surface roughness were used as machinability criteria and a new model of machinability was evaluated.

The results of the investigation of untreated $\mathrm{C} 45 \mathrm{E}$ carbon steel (45 HRc) with the carbide cutting tool are as follows:

- The application of HPJAM reduces the value of feed and passive cutting force by about $7 \%$ in comparison with CLF.

- $\quad$ MQL and HPJAM provide favorable shapes of chips under all analyzed machining conditions; MQL provides good lubrication conditions, but low cooling effects of the cutting zone. The HPJAM application provides excellent lubrication and cooling conditions.

- Tool wear in HPJAM is uniform and less notch wear is recognized compared to other two CLF delivery techniques. When HPJAM was applied, tool life was almost three times longer compared to MQL and almost four times longer than when conventional flooding was applied.

- Lower surface roughness was achieved with the application of conventional flooding, while not much difference in roughness was perceived between MQL and HPJAM.

- From the region-of-operability point of view, the HPJAM technique offers a wider area of machining and the chips were bright, which indicates that the generated heat was removed from the cutting zone with CLF.

The results of the investigation on surface hardened carbon steel C45E (58 HRc), with A12O3 coated carbide cutting tools show that with the application of HPJAM the following improvements can be achieved:

- Feed and passive cutting forces were about $10 \%$ lower than when conventional flooding was applied, while the main cutting force was the same under all cooling and lubrication conditions;

- The distribution of wear along the flank face appears to be uniform in both cases (conventional flooding and HPJAM).

- For the selected criteria, in the case of HPJAM tool life was approximately five times longer than in the case of conventional cooling. It should be pointed out that the consumption of coolant in the case of HPC is more than four times lower than in the case of conventional cooling.

- The expansion of the region of operability is evident especially in hardened steel machining, which enables higher productivity and superior chip breakability to be achieved in all conditions, as well as BUE reduction at lower speeds.

- For both CLF delivery techniques (conventional flooding and HPJAM) similar surface roughness was obtained. 
- The most important concluding remarks regarding the advantages of HPJAM over conventional flooding in hard turning of steel with coated carbide tools is that the region of operability for a given tool-material pair is extended. An approximately $45 \%$ increase in the maximum achievable cutting speed and a $25 \%$ increase in the maximum achievable feed rate were proven.

The results presented in this paper show that in all cases, regardless of the material type, HPJAM gives superior machinability compared to other two CLF delivery techniques. For the creation and further development of machinability databases and expert systems, it is necessary to expand the area of cutting conditions, workpiece materials and tools.

\section{ACKNOWLEDGEMENT}

This research is the result of a bilateral project BI-BA/14-15-001 between Slovenia and Bosnia and Herzegovina with collaboration between the Laboratory for Cutting at FME Ljubljana and the Laboratory for cutting and machining systems at FME Banja Luka.

\section{REFERENCES}

[1] W. Grzesik: Advanced machining processes of metallic materials: theory, modelling and application. Elsevier B. V., Amsterdam 2008.

[2] B. Lauwers: Surface Integrity in Hybrid Machining Processes, Procedia Eng. 19, 241-251 (2011). DOI: 10.1016/j.proeng.2011.11.107

[3] F. Pušavec: Porous tungsten machining under cryogenic conditions. Int. journal of refractory \& hard metals 35, 84-89 (2012). DOI: 10.1016/j.ijrmhm.2012.04.009

[4] F. Čuš, U. Župerl: Surface roughness control simulation of turning processes, Strojniški vestnik 61, no.4 245-253 (2015)

[5] E. Kuljanic, M. Sortino, G. Totis: Machinability of difficult machining materials. Proceedings of the 14th TMT 2010, Mediterranean Cruise 2010, 1-14.

[6] A. E. Diniz, R. Micaroni: Influence of the Direction and Flow Rate of the Cutting Fluid on Tool Life in Turning Process of AISI 1045 Steel. Int. J. of Machine Tools \& Manufacture 47, no. 2, 247-254 (2007). DOI: 10.1016/j.ijmachtools.2006.04.003

[7] V. Sahma, M. Dogra, N. Suri: Cooling techniques for improved productivity in turning. Int. J. of Machine Tool \& Manufacturing 49, no. 6, 435-453 (2010).

[8] R.W. Maruda, E. Feldshtein, S. Legutko, G.M. Krolczyk: Research on emulsion mist generation in the conditions of minimum quantity cooling lubrication (MQCL). Tehnicki Vjesnik - Technical Gazette. 22, $1165-1169$ (2015).

[9] R.W. Maruda, G.M. Krolczyk, E. Feldshtein, F. Pusavec, M. Szydlowski, S. Legutko, et al.: A study on droplets sizes, their distribution and heat exchange for minimum quantity cooling lubrication (MQCL). International Journal of Machine Tools and Manufacture 100, 81 - 92 (2016). DOI: 10.1016/j.ijmachtools.2015.10.008

[10] A. Duchosal, S. Werda, R. Serra, R. Leroy, H. Hamdi: Numerical modeling and experimental measurement of MQL impingement over an insert in a milling tool with inner channels. International Journal of Machine Tools and Manufacture 94, 37-47 (2015). DOI: 10.1016/j.jimachtools.2015.04.003

[11] K. Nadolny, M. Wojtewicz, W. Sienicki, D. Herman: An analysis of centrifugal MQL supply system potential in the internal cylindrical grinding process. Arch. Civil Mech. Eng. 15, no. 3, 639-649 (2015). DOI: $10.1016 /$ j.acme.2014.08.009

[12] D. Jia, C.Li, D.Zhang, S.Wang, Y.Hou: Investigation into the formation mechanism and distribution characteristics of suspended microparticles in MQL grinding. Recent Pat, Mech. Eng. 7, 52-62 (2014).

[13] P. Dahlman, M. Escursell: High-Pressure Jet-Assisted Cooling: A New Possibility for Near Net Shape Turning of Decarburized Steel. Int. J. of Machine Tools \& Manufacture 44, no. 1, 109-115 (2004). DOI: $10.1016 / \mathrm{S} 0890-6955(03) 00058-0$

[14] D. Kramar, J. Kopac: High pressure cooling in the machining of hard-to-machine materials. Journal of Mechanical Engineering 55, no. 11, 685-694 (2009). 
[15] C. Courbon, D. Kramar, P. Krajnik, F. Pusavec, J. Rech, J. Kopac: Investigation of machining performance in high-pressure jet assisted turning of Inconel 718: an experimental study. Int. J. of Machine Tools \& Manufacture 49, no. 14, $1114-1125$ (2009). DOI: 10.1016/j.ijmachtools.2009.07.010

[16] W. Boulger, M. L. Shaw, H. E. Johnson: Constant Pressure Lathe Test for Measuring the Machinability of Free-Machining Steels. Transactions of ASME, 71, 431- 438 (1949).

[17] E. H. Lee, B. W. Shaffer: The Theory of Plasticity Applied to a Problem of Machining. J. Appl. Mech., 18, no. 4, 405 (1951).

[18] S. Enache, E. Strajescu, C. Opran, C. Minciu, M. Zamfirache: Mathematical model for the establishment of material machinability. Annals of CIRP 44, no. 1, 79-82 (1995). DOI: 10.1016/S0007-8506(07)62279-3

[19] R. V. Rao, O. P Gandhi: Diagraph and matrix methods for machinability evaluation of work material. Int. J. of Machine Tools \& Manufacture 42, no. 3, 321-330 (2002). DOI: 10.1016/S0890-6955(01)00133-X

[20] G. Globocki-Lakic, B. Sredanovic, B. Nedic, D. Cica, D. Catic: Development of mathematical model of universal material machinability. J. of the Balkan Tribological Association 17, no. 4, 501-511 (2011).

[21] E. W. Theile, K. J. Kuding, D. W. Murphy, G. Soloway, B. Duffin: Comparative machinability of brasses, steel and aluminum alloy: CDA's universal machinability index. Publishing of CDA in New York, Report (1990).

[22] AFNOR Standart NF E 66-520, Couple outil-matière, Domaine de fonctionnement des outils coupants. vols. 1-6 (1994).

Submitted: $\quad 28.8 .2015$

Accepted: $\quad 10.5 .2016$
Gordana Globočki - Lakić ${ }^{1}$

Branislav Sredanović ${ }^{1}$

Davorin Kramar ${ }^{2}$

Janez Kopač ${ }^{2}$

${ }^{1}$ University of Banjaluka, Faculty of Mech. Engineering, Stepe Stepanovića 71, 78000 Banjaluka, Bosnia and Herzegovina ${ }^{2}$ University of Ljubljana, Faculty of Mech. Engineering, Aškerčeva 6, 1000 Ljubljana, Slovenia 